\title{
Screening practices of Australian men and women categorised as "at or slightly above average risk" of colorectal cancer
}

\author{
Driss AIT OUAKRIM ${ }^{\mathrm{a}}$, Trevor LOCKETT ${ }^{\mathrm{b}}$, Alex BOUSSIOUTAS ${ }^{\mathrm{c}}$, Louise KEOGH ${ }^{\mathrm{d}}$, Louisa B. \\ FLANDER $^{\mathrm{a}}$, Ingrid WINSHIP ${ }^{\mathrm{e}}$, Graham G. GILES $^{\dagger}$, John L. HOPPER ${ }^{\mathrm{a}}$, and Mark A. JENKINS ${ }^{\mathrm{a}}$ \\ ${ }^{a}$ Centre for Molecular, Environmental, Genetic \& Analytic Epidemiology, the University of \\ Melbourne, Victoria 3010, Australia \\ bPreventative Health national Research Flagship, CSIRO Food and Nutritional Sciences - North \\ Ryde, NSW 2113, Australia
}

'Peter MacCallum Cancer Centre, 3002 Melbourne, Australia

'Centre for Women's Health, Gender and Society, the University of Melbourne, Victoria 3010, Australia

eGenetic Medicine, The University of Melbourne and The Royal Melbourne Hospital, Parkville, Victoria 3050, Australia

${ }^{f}$ Cancer Epidemiology Centre, Cancer Council Victoria, Carlton, Victoria 3053, Australia

\section{Abstract}

Purpose-Australia has one of the highest incidences of colorectal cancer (CRC) in the world. In 2006, the federal government introduced a screening programme consisting of a one-off faecal occult blood test offered to people turning 50,55 or 65 years. We conducted a population-based study to estimate CRC screening practices existing outside the current programme.

\begin{abstract}
Methods - 1887 unaffected subjects categorised "at or slightly above average risk" of CRC were selected from the Australasian Colorectal Cancer Family Registry. We calculated proportions of participants that reported appropriate, under- and over-screening according to national guidelines. We performed a logistic regression analysis to evaluate associations between over-screening and a set of socio-demographic factors.
\end{abstract}

Results-Of 532 participants at average risk of CRC, eligible for screening, $4(0.75 \%)$ reported appropriate screening, 479 (90\%) reported never having been screened, 18 (3\%) reported some but less than appropriate screening and $31(6 \%)$ reported over-screening. Of 412 participants aged 50 years or over, slightly above average risk of CRC, 1 participant $(0.25 \%)$ reported appropriate screening, $316(77 \%)$ reported no screening and $11(3 \%)$ reported some but less than appropriate screening. Among participants under age 50 years, $2 \%$ of those at average risk, and $10 \%$ of those slightly above average risk reported over screening. Middle-aged people, those with a family history of CRC and those with a university degree were more likely to be over-screened.

Conclusion-Overall, the level of CRC screening participation was low and the vast majority of screening tests undertaken were inappropriate in terms of timing, modality or frequency.

Corresponding author: Driss Ait Ouakrim, PhD, Centre for Molecular, Environmental, Genetic \& Analytic Epidemiology, School of Population Health, Level 3, 207 Bouverie Street, The University of Melbourne, VIC 3010, Australia, Tel: +61 390353336 ; Fax: +61 39349 5815,drissao@unimelb.edu.au.

Conflict of interest statement:

The authors declare that there are no conflicts of interest. 


\section{Introduction}

Colorectal cancer (CRC) is a major heath problem. It is the third most common cancer for both men and women and accounts for approximately $9.8 \%$ of total cancer cases and $8.1 \%$ of total cancer deaths worldwide. In 2008, over 1.2 million people were diagnosed with the disease and more than six hundred thousand died from it [1]. Three randomised controlled trials conducted in the 1990s demonstrated the effectiveness of screening-by faecal occult blood tests followed by a diagnostic colonoscopy - to reduce CRC incidence and mortality for people at average risk of the disease, i.e. not selected because of specific, personal risk factors [2-4]. The results of these studies and predictions of an increase in the burden of CRC due to ageing populations [5], pushed many countries to engage in a global public health effort to prevent the disease by implementing mass screening programmes [6]. As of 2004, there were at least 35 different CRC screening initiatives in 17 countries, including 10 routine population-based screening programmes, 9 pilots and 16 research projects [7].

In 2007, 14,234 CRC diagnoses and over 4047 deaths due to this disease were reported for Australia [8]. With an average of 45.1 new cases per 100,000 individuals diagnosed that year, Australia has one of the highest national age-standardised rates of CRC in the world. This has been the case for both men and women for the last two decades [1]. Australia has been engaged in a CRC prevention policy for more than 13 years, since the publication in 1997 by the Australian Health Technology Advisory Committee (AHTAC) of an expert report recommending the implementation of CRC screening programme [9]. In 1999, Australia's peak medical research body, the Australian National Health and Medical Research Council (NHMRC), published guidelines for the prevention, early detection and management of bowel cancer [10] (updated in 2002 and 2005) recommending biennial faecal occult blood test (FOBT) from age 50 years for people categorised "at or slightly above average risk" of the disease, which is the lowest category of risk assigned by the guidelines. In 2006, the federal government introduced a national bowel cancer screening programme (NBCSP). In its current form and through to 2014, the NBCSP offers, free of charge, a once only faecal immune test (a modified FOBT) for people turning 50, 55 or 65 years of age to perform in the privacy of their own home [11]. Despite the program only providing screening for a small fraction of those 50 and over, i.e. less than recommended by the NHMRC guidelines, there remains a general consensus amongst medical professionals that the NBCSP provides a valuable step towards a fully implemented population screening programme while still falling well short of the recommended biennial screening for people in this age group [12-15].

Studies conducted in other countries have consistently documented low uptake of CRC screening and identified several barriers to people's participation in CRC screening [16-19]. Consistent with the international experience, the data from the NBCSP suggest that only around $40 \%$ of people invited to screen actually perform the test. Further, as we have only a very limited understanding of what the Australian screening practices are outside of the NBCSP, we have no baseline reference for CRC screening data against which the performance of the NBCSP can be compared.

Our goal was to describe CRC screening practices specific to people categorised "at or slightly above average risk" of the disease, as per their family history of CRC, by analysing self-reported screening data for participants in the Australasian Colorectal Cancer Family Registry (ACCFR) study. We report population-based and test-specific screening participation levels and the associations between screening and a set of socio-demographic factors provided by the participants. 


\section{Material and methods}

\section{Subjects}

This study is based on a population sample from the ACCFR which is a large case-controlfamily study and part of an international consortium funded by the United States National Cancer Institute, designed to address specific research questions of colorectal cancer aetiology. Details of the method have been reported elsewhere [20].

In brief, participants were recruited via population-based case-probands and populationbased control-probands. Case-probands were residents of the Melbourne metropolitan area between 1997 and 2001 who were diagnosed when aged between 18 and 59 years with an incident first primary adenocarcinoma of the colorectum (CRC) and identified by the Victorian Cancer Registry. People having had a previous diagnosis of CRC or FAP were excluded. Attempts were made to recruit adult first- and second-degree relatives (parents, siblings, offspring, aunts, uncles and grandparents) of all case-probands as well as their spouses/partners. In addition, all first-degree relatives of any participant with a diagnosis of $\mathrm{CRC}$ were sequentially ascertained. Approaches to the relatives of case-probands were made after obtaining permission from the probands to contact these relatives.

Population control-probands, frequency matched to the age and sex of the case-probands, and registered as living in the Melbourne metropolitan area, were identified from the federal electoral register (registering to vote is compulsory for all Australians 18 years-old and over). Similarly to the case-probands, control-probands were asked permission to contact their first-and second-degree relatives regarding participation in the ACCFR. Figure 1 summarises the ACCFR subject recruitment and participants' selection to the current study.

\section{Data collection}

A risk factor questionnaire and a family history of cancer questionnaire were administered to all participants at baseline. Questionnaires were administered by face-to-face interviews with the probands and telephone interviews with their relatives. All participants were asked to provide information on:

- demographics (age, sex, date of birth, marital status, education, postcode relationship to proband, proband's vital status and date of death if deceased);

- personal medical history (history of diabetes, high blood cholesterol level, irritable bowel syndrome, FAP, history of cancer);

- family history of cancer, including CRC (age, sex, date of birth, type of cancer, age at diagnosis for each first- and second-degree relative);

- history of faecal occult blood test (FOBT), sigmoidoscopy and colonoscopy including: reason for their first test (to investigate a new problem; family history of CRC; routine check up; follow-up of previous problem; other); their age when they first had a test; the number of separate tests they have had; and if more than one test, their age when they last had a test.

Attempts were made to verify all reports of CRC in families against medical records, death certificates, pathology reports and cancer registry data. Of the relatives of the probands we identified 150 CRC cases of which 95 (63.3\%) have been verified and $55(36.7 \%)$ remain unconfirmed. 


\section{Risk categorisation}

All participants with no personal history of colorectal cancer, i.e. the control-probands and the unaffected relatives of case- and control-probands, were classified into one of four CRC risk categories based on their family history of CRC, according to NHMRC guidelines [10]:

- “Average risk"(no personal history of bowel cancer, advanced adenoma, or chronic ulcerative colitis and no confirmed bowel cancer in close family);

- "Slightly above average risk" (one first or second degree relative with bowel cancer diagnosed at age 55 or older or two relatives diagnosed with bowel cancer at age 55 or older but on different sides of the family);

- "Moderately increased risk" (one first-degree relative with CRC diagnosed before the age of 55 years or, two first- or one first- and one second-degree relative(s) on the same side of the family with CRC diagnosed at any age);

- "Potentially high risk" (three or more first-degree relatives or, a combination of first-and second-degree relatives on the same side of the family diagnosed with CRC or, two or more first- or second-degree relatives on the same side of the family diagnosed with CRC including any of the following features (first- or second-degree relative with multiple CRC, first- or second-degree relative who has/ had an Lynch Syndrome-related cancer (such as endometrial, ovarian, stomach, small bowel, renal pelvis or ureter, biliary tract or brain cancer) [21].

Participants with a personal history of CRC and those with no personal history of disease but classified as "at moderately increased risk" or "at potentially high risk" were excluded from this study, leaving only those, "at or slightly above average risk".

\section{Screening participation}

Screeners were defined as those participants who reported having ever undergone a FOBT, sigmoidoscopy or colonoscopy as a regular check-up or because of their family history of CRC. Non-screeners were defined as those participants who did not report any screening or those who had reported having undergone FOBT, sigmoidoscopy or colonoscopy but only to investigate a new problem or as follow-up of a previous problem (i.e. we assumed that the tests for these participants were diagnostic). Screening participation was classified as either: less than appropriate screening; appropriate screening; or over-screening based on the existing NHMRC guidelines for the specific risk group [10].

For both categories of risk: "at average risk" and "slightly above average risk", appropriate screening for participants aged 50 years and older, was defined as having one screening FOBT every 2 years or one sigmoidoscopy every 5 years. For these participants less than appropriate screening was defined as never having had a CRC screening procedure or having undergone a screening FOBT more than two years prior to interview or a sigmoidoscopy more than five years prior to interview. Over-screening was interpreted as having ever had a "screening" colonoscopy or having had a FOBT or a sigmoidoscopy with intervals of less than 2 and 5 years respectively.

For participants in the "at or slightly above average risk" group aged less than 50 years, appropriate CRC screening was defined as never having undergone a screening procedure. For these participants therefore, under-screening was not possible and over-screening was defined as ever having had any screening test.

Radiological colonography was not considered as part of this study due to its rare use as a screening tool and that it is a non-rebated (therefore difficult to confirm) investigation for this indication in Australia. 


\section{Statistical analysis}

Proportions of participants that reported appropriate, less than appropriate and over screening were calculated by age group and CRC risk category for each screening modality. Participants in each risk category were compared using the Pearson ${ }^{2}$ test of independence.

A logistic regression analysis, was performed to estimate the association, as odds ratios $(\mathrm{OR})$ and their 95 percent confidence intervals $(\mathrm{CI})$, between the outcome: over-screening and the explanatory variables: age, education (tertiary vs. other), marital status (married or living as married vs. other), socioeconomic status defined using participants' residential postcode and the 2001 index of relative socio-economic disadvantage (IRSD) [22] (1-4 most disadvantaged deciles vs. $5-7$ moderately disadvantaged deciles vs. $8-10$ least disadvantaged deciles), family history of CRC defined as having at least one first- or second-degree relative diagnosed with CRC (yes vs. no), regular physical activity (at least 30 minutes a week for a minimum of 3 consecutive months in the most recent decade of life vs. less activity), body mass index $\left(<25 \mathrm{~kg} / \mathrm{m}^{2} \mathrm{vs} .225 \mathrm{~kg} / \mathrm{m}^{2}\right.$ ), cigarette smoking (exsmoker vs. current smoker vs. never smoked), number of years lived in Australia ( $>20$ years vs. 20 years), diabetes (affected vs. non-affected), high cholesterol (affected vs. nonaffected), and personal history of any cancer apart from CRC (yes vs. no). These variables were selected based on prior studies suggesting an association with either CRC risk or screening practices $[23,24]$.

Variables with a p-value $₫ 0.25$ in the univariate analysis were selected for inclusion in a multivariate analysis. A parsimonious model was determined by including variables significant at a p-value of 0.05 . We used clustered robust standard errors to account for intra-class correlation due to non-independence of family members. For all variables, any records including a response that was described as "missing" or "do not know" were excluded from all analyses. Participants who did not provide sufficient information on screening practices were also excluded from the analysis. All statistics were calculated using STATA version 11.

\section{Results}

Of 3845 participants who completed the baseline questionnaire, 1887 participants (50.3\%) met the inclusion criteria for having no diagnosis of CRC and being either, at or slightly above average risk of developing CRC. Table 1 shows participants' characteristics by risk category.

\section{Participants "at average risk" of CRC}

Based on their family history of colorectal cancer, 1037 participants were categorised as being at average risk of CRC. Of these, $532(51 \%)$ were aged 50 years or over and, therefore, eligible for screening by the existing screening guidelines. Of these, 479 (90\%) reported never having been screened, 18 participants (3\%) reported some, but less than appropriate, CRC screening. Only 4 participants $(0.75 \%)$ reported a modality and frequency of screening consistent with appropriate screening and 31 participants (6\%) were categorised as "over-screeners" due to the use of colonoscopy as the screening procedure (fig. 2a). For those aged less than 50 years and, therefore, not recommended to have any screening, 12 participants (2\%) reported having undergone a CRC screening procedure (tables 2 and 3).

\section{Participants "at slightly above average risk" of CRC}

850 participants were categorised as being slightly above average risk of CRC. There were 412 participants aged over 50 years in this risk group of whom 316 (77\%) reported no screening and 11 (3\%) reported some, but less than appropriate, screening. Only 1 
participant $(0.25 \%)$ reported appropriate screening, as defined by the existing guidelines. Over-screening practices were identified for 84 (20\%) participants older than 50 years. For people aged less than 50 years, $395(90 \%)$ reported no CRC screening which is appropriate for this age category, but $43(10 \%)$ underwent a CRC screening procedure, which for $90 \%$ of these participants, was a colonoscopy (fig $2 \mathrm{~b}$ ).

\section{Factors associated with CRC screening}

The factors associated with over-screening are summarised in table 3 . The likelihood of over-screening increased markedly with age. Participants aged 40 to 69 years old were between five and seven times more likely to be over-screened compared with those aged 18 to 39 years old. Having a high level of cholesterol was also a significant predictor for overscreening. Participants with a tertiary education were almost twice as likely to be overscreened. Family history of CRC was also a strong predictor of over-screening. Participants with a first- or second-degree relative diagnosed with CRC were at least five times more likely to have a colonoscopy as a primary screening procedure.

\section{Discussion}

We report the first population-based estimate of CRC screening participation for Australian adults considered to be "at or slightly above average risk" of the disease, using a guidelinederived definition of CRC screening. In reality, given that a substantial proportion of the population must be below the mean for risk of CRC, this category also includes those below the average risk of developing the disease. Overall, we identified a very low level of appropriate CRC screening uptake by eligible people. Of those recommended biennial FOBT or 5-yearly sigmoidoscopy, around eight in ten reported never have had any screening procedure and only one in 200 participants reported having had appropriate CRC screening. For those not recommended to have any screening, one in 16 reported having had a screening procedure, a large majority $(80 \%)$ being people with a family history of CRC.

Estimates of CRC screening uptake from the current study are consistent with previous reports of CRC screening participation for the Australian population. Cockburn et al. estimated screening participation by people aged over 50 years to be around $10 \%$ for screening endoscopy [25] compared with $12 \%$ in our study. Other reports have estimated the level of FOBT screening between 4\% and 20\% [26] [27] compared with 5\% in our study. Comparability of these estimates with our findings and across studies is difficult given investigators having used different conceptual and operational definitions of CRC screening.

In our analysis we distinguished between participants at average- and those at slightly above average-risk of CRC, based on the terminology and classification used in the NHMRC guidelines [10]. We found that CRC screening participation was extremely low for both subcategories. We also observed that most of the over-screening was reported by participants who were at slightly above average-risk. That is, one person in five for participants aged 50 years or older, and one in ten for those aged less than 50 years. This corresponds to more than $90 \%$ of the screening procedures reported by screeners in this risk-group, compared with $66 \%$ of the procedures reported by those at average-risk of CRC. Overall, these results show that a large proportion of screeners with no or a relatively weak family history of CRC had an endoscopic procedure (mainly colonoscopy given that less than $1 \%$ of the screeners reported having had a sigmoidoscopy) as their primary CRC screening modality. This can be related to a poor understanding among clinicians of how the risk of CRC varies with history of the disease in the patient's family. More research is needed to measure the impact of these unnecessary tests in terms of cost and potential harm for people receiving them. 
One of the main strengths of our study is its use of a guideline-based definition of CRC screening participation. This was possible because of the family-based design of the ACCFR and our systematic data collection from all participants and systematic attempts to validate information provided by relatives. Also, unlike previous studies, we have been able to discriminate between screening and diagnostic procedures and to exclude people with above average risk of CRC from the analysis. This approach provides accurate and reliable screening estimates, and allows an understanding of their potential public health impact [28].

There are several plausible explanations for the low level of CRC screening participation observed. A survey of one thousand persons aged 40 to 60 years living in Victoria in 1998 has shown that there was a poor understanding of CRC screening by people at average-risk, with only $12 \%$ indicating any knowledge of FOBT screening [29]. Lack of CRC screening awareness among doctors might also explain the low level of screening participation observed. It has been shown that medical practitioners are often not familiar with CRC screening guidelines or not proactive in implementing them [30] and several studies have demonstrated that patients' compliance with guidelines is unlikely without the influence and encouragement of their doctor [31,32]. A study of 213 general practitioners in Western Australia found that $67 \%$ believed that screening was not warranted for any people at average risk of CRC [33]. More generally, the low level of CRC screening reported in this current study by the ACCFR participants, along with the over-screening practices observed for more than $12 \%$ of screen-eligible people, might reflect confusion among patients and physicians, and the lack of coherence in the Australian CRC prevention policy.

As the first version of the NHMRC guidelines on CRC screening was introduced in 1999, two years after the beginning of the ACCFR recruitment phase and three years before the final recruitment of participants for this analysis, it is not possible to ascribe all the inappropriate screening to under-utilization of the guidelines. Another limitation is that our analysis is based on a one-time survey of participants so we do not know whether personal screening practices have changed over time. A longitudinal study is needed to fully determine peoples' screening behaviour. The ACCFR is currently conducting follow-up surveys of all participants five-years after recruitment and these data will be available in due course.

It is possible that the current level of CRC screening of the general population is higher than the estimates reported in this study. Results from the New South Wales Health Survey Programme have estimated that in 2009 nearly $20 \%$ of adults aged 50 and over had a screening FOBT in the last two years before interview [34]. In a community survey conducted in the Hunter region, New South Wales, Courtney and colleagues also found a $20 \%$ participation rate to FOBT screening [35], compared with less than $1 \%$ in our study. However, a direct comparison with our results may not be appropriate as in both studies failed to ascertain family history of CRC, therefore a proportion of the survey participants may have been incorrectly categorised as "at or slightly above average risk". Overall, one can assume that the consensus among health professionals, which has led to the publication of the NHMRC guidelines, has certainly improved consistency in screening recommendations by clinicians [14]. The introduction of the NBCSP might also have contributed to increased CRC screening awareness and participation by the population.

We consider that our results remain relevant to the current pattern of Australian CRC screening behaviour, as the impact of the national guidelines and the NBCSP, in terms of CRC screening participation improvement as recommended by the NHMRC guidelines, has been limited. First, the publication of practice guidelines is insufficient, on its own, to change patients' medical behaviour $[36,16]$. Second, the inconsistencies between the local 
and the different international CRC screening guidelines available might have, and continue to generated confusion among doctors and prevent them from implementing the appropriate recommendations [37] which might explain the high level of colonoscopy screening reported by participants in their survey. Third, the $40 \%$ participation (37\% for men and $43 \%$ for women) in the NBCSP in 2009 [38] indicates the limited impact that the current programme has had since its introduction, which might reflect the population's low level of CRC screening awareness or acceptability of the screening procedure.

A large number of studies have investigated and identified lifestyle, health and sociodemographic characteristics associated with CRC screening in the general population [3943]. Among these characteristics, male gender, older age, marital status, higher education, higher income, urban area of residence and ethnicity have been consistently identified as predictors of screening uptake. Other predictors include: smoking history, chronic disease and family history of CRC as well as healthcare access, delivery and utilisation factors [42]. None of the current studies however have investigated over-screening and its potential predictors. To our knowledge, this is the first study to investigate the predictors of overscreening for CRC in the general population. We found that older age was the strongest predictor of over-screening. Participants with a family history of CRC and those who had a university education were also more likely to be over-screened. This suggests that there is confusion around the notion of family history of CRC in the general population and a limited understanding of the true disease risk related to it.

In a recent systematic review, Holden and colleagues highlighted the lack of research on the problem of over-screening [44]. Our study contributes to addressing this gap. Future research on CRC screening practices should systematically include over-screening as a possible behaviour and measure its prevalence in the population. This could lead to the identification of additional predictors of over-screening and overall, allow a better monitoring of the CRC screening activity in the population.

Our findings of low screening uptake might be alarming but are overall in line with trends observed in previous Australian and international studies. The quasi-absence of appropriate screening participation among screen-eligible people and the significant amount of overscreening reported show that the current guidelines are not being implemented. Further, over-screening utilises resources that could be used to improve screening and follow-up for eligible people [45]. It also unnecessarily exposes people to potential adverse events associated with screening and more particularly with colonoscopy screening [46].

In this sense, our findings highlight the gaps in the Australian CRC screening prevention policy and are of particular relevance given the steady increase in CRC incidence that has been observed in Australia for the last 20 years despite a continuous increase in the number of colonoscopies performed [47,14]. Effective screening strategies known be beneficial to the population exist and there is an urgent need for researchers and health policy makers to develop methods to implement them, and overall improve the appropriate use and quality of CRC screening [44]. As for the current NBCSP and the uncertainties surrounding its full implementation and funding beyond 2015 [48-50], our results constitute a good indicator of what CRC screening participation might be in a system based on opportunistic screening. Our results call for the necessity of a fully implemented and evidence-based CRC screening programme where significant progress in CRC prevention can be achieved.

\section{Acknowledgments}

The authors thank Kelly Aujard for her assistance with variable design and ascertainment. This study was supported by the NIH (National Cancer Institute grants RFA CA-95-011, UO1 CA097735). Driss Ait Ouakrim was supported 
by a Commonwealth Scientific and Industrial Research Organisation PhD scholarship (CSIRO, Preventative Heath Flagship). The study was conducted independently of funding agencies.

\section{References}

1. Ferlay, JSH.; Bray, F.; Forman, D.; Mathers, C.; Parkin, DM. GLOBOCAN 2008, cancer incidence and mortality woeldwide. IARC CancerBase no 10. http://globocan.iarc.fr/

2. Hardcastle JD, Chamberlain JO, Robinson MH, Moss SM, Amar SS, Balfour TW, James PD, Mangham CM. Randomised controlled trial of faecal-occult-blood screening for colorectal cancer. Lancet. 1996; 348(9040):1472-1477. S0140-6736(96)03386-7 [pii]. 10.1016/ S0140-6736(96)03386-7 [PubMed: 8942775]

3. Kronborg O, Fenger C, Olsen J, Jorgensen OD, Sondergaard O. Randomised study of screening for colorectal cancer with faecal-occult-blood test. Lancet. 1996; 348(9040):1467-1471. S0140-6736(96)03430-7 [pii]. 10.1016/S0140-6736(96)03430-7 [PubMed: 8942774]

4. Mandel JS, Bond JH, Church TR, Snover DC, Bradley GM, Schuman LM, Ederer F. Reducing mortality from colorectal cancer by screening for fecal occult blood. Minnesota Colon Cancer Control Study. N Engl J Med. 1993; 328(19):1365-1371.10.1056/NEJM199305133281901 [PubMed: 8474513]

5. Karsa LV, Lignini TA, Patnick J, Lambert R, Sauvaget C. The dimensions of the CRC problem. Best Pract Res Clin Gastroenterol. 2010; 24(4):381-396. S1521-6918(10)00065-X [pii]. 10.1016/ j.bpg.2010.06.004 [PubMed: 20833343]

6. Rozen P, Winawer SJ, Waye JD, Burnand B, Harris JK, Wietlisbach V, Froehlich F, Vader J-P, Gonvers J-J, Joseph DA, DeGroff AS, Hayes NS, Wong FL, Plescia M, Shapero TF, Hoover J, Paszat LF, Burgis E, Hsieh E, Rothwell DM, Rabeneck L, Hilsden RJ, Lansdorp-Vogelaar I, van Ballegooijen M, Zauber AG, Boer R, Wilschut J, Habbema JDF, Armelao F, Paternolli C, Franceschini G, Franch R, Orlandi PG, Miori G, Avancini I, Togni M, Rossi M, Meggio A, Tasini E, Manfrini R, Giacomin D, Fasoli R, Faitini K, Mastromauro M, Costa S, Ridolfi F, Rosi P, de Pretis G, Bressler B, Lo C, Amar J, Whittaker S, Chaun H, Halparin L, Enns R, Brenner H, Altenhofen L, Hoffmeister M, Thiis-Evensen E, Seip B, Vatn MH, Hoff GS. the ESG. Prospects for the worldwide control of colorectal cancer through screening. Gastrointest Endosc. 2002; 55 (6): 755-759. [PubMed: 11979269]

7. Benson VS, Patnick J, Davies AK, Nadel MR, Smith RA, Atkin WS. Colorectal cancer screening: a comparison of 35 initiatives in 17 countries. Int J Cancer. 2008; 122(6):1357-1367.10.1002/ijc. 23273 [PubMed: 18033685]

8. Australian Institute of Health and Welfare (AIHW). ACIM (Australian Cancer Incidence and Mortality) Books. AIHW; Canberra: 2010.

9. Commonwealth Department of Health and Family Services, Australian Health Techonology Advisory Committee. Colorectal cancer screening. Canberra: Australian Government Publishing Service; 1997.

10. National Health and Medical Research Council. Clinical practice guidelines for the prevention, early detection and management of colorectal cancer. Canberra: NHMRC; 2005. Available at: http://www.nhmrc.gov.au/publications/synopses/cp62syn.htm

11. Australian Gorvernment Departement of Health and Ageing. National Bowel Cancer Screening Program. website at http://www.cancerscreening.gov.au. http://www.cancerscreening.gov.au/

12. Cancer Council Australia. Cancer control priorities for the 2009-10 federal budget. p. 368152Available at: http://www.cancer.org.au/policy/submissionstogovernment/ archivegovsubmissions/2009.htm

13. Olver, I. Editorial "We can beat bowel cancer". Editorial. 2011. Available at: http:// www.aprs.com.au/australian-health-news/we-can-beat-bowel-cancer

14. Young GP. Population-based screening for colorectal cancer: Australian research and implementation. J Gastroenterol Hepatol. 2009; 24(Suppl 3):S33-42. JGH6069 [pii]. 10.1111/j. 1440-1746.2009.06069.x [PubMed: 19799696]

15. Javanparast S, Ward P, Young G, Wilson C, Carter S, Misan G, Cole S, Jiwa M, Tsourtos G, Martini A, Gill T, Baratiny G, Matt MA. How equitable are colorectal cancer screening programs 
which include FOBTs? A review of qualitative and quantitative studies. Prev Med. 2010; 50(4): 165-172. S0091-7435(10)00058-7 [pii]. 10.1016/j.ypmed.2010.02.003 [PubMed: 20153359]

16. Rabeneck L, Paszat LF. A population-based estimate of the extent of colorectal cancer screening in Ontario. Am J Gastroenterol. 2004; 99(6):1141-1144. AJG30623 [pii]. 10.1111/j. 1572-0241.2004.30623.x [PubMed: 15180738]

17. Ritvo P, Myers R, Del Giudice ME, Pazsat L, Cotterchio M, Howlett R, Mai V, Brown P, Sullivan T, Rabeneck L. Fecal occult blood testing: people in Ontario are unaware of it and not ready for it. Can Fam Physician. 2009; 55(2):176-177. e174. 55/2/176 [pii]. [PubMed: 19221081]

18. Seeff LC, Nadel MR, Klabunde CN, Thompson T, Shapiro JA, Vernon SW, Coates RJ. Patterns and predictors of colorectal cancer test use in the adult U.S. population. Cancer. 2004; 100(10): 2093-2103.10.1002/cncr.20276 [PubMed: 15139050]

19. Shapiro JA, Seeff LC, Thompson TD, Nadel MR, Klabunde CN, Vernon SW. Colorectal cancer test use from the 2005 National Health Interview Survey. Cancer Epidemiol Biomarkers Prev. 2008; 17(7):1623-1630. 17/7/1623 [pii]. 10.1158/1055-9965.EPI-07-2838 [PubMed: 18628413]

20. Newcomb PA, Baron J, Cotterchio M, Gallinger S, Grove J, Haile R, Hall D, Hopper JL, Jass J, Le Marchand L, Limburg P, Lindor N, Potter JD, Templeton AS, Thibodeau S, Seminara D. Colon Cancer Family Registry: an international resource for studies of the genetic epidemiology of colon cancer. Cancer Epidemiol Biomarkers Prev. 2007; 16(11):2331-2343. 1055-9965.EPI-07-0648 [pii]. 10.1158/1055-9965.EPI-07-0648 [PubMed: 17982118]

21. Vasen HF, Watson P, Mecklin JP, Lynch HT. New clinical criteria for hereditary nonpolyposis colorectal cancer (HNPCC, Lynch syndrome) proposed by the International Collaborative group on HNPCC. Gastroenterology. 1999; 116 (6):1453-1456. [PubMed: 10348829]

22. Australian Bureau of Statistics. 2001 Census of Population and Housing - SEIFA. 2001. http:// www.abs.gov.au/websitedbs/D3310114.nsf/home/Seifa_entry_page

23. Beydoun HA, Beydoun MA. Predictors of colorectal cancer screening behaviors among averagerisk older adults in the United States. Cancer Causes Control. 2008; 19(4):339-359.10.1007/ s10552-007-9100-y [PubMed: 18085415]

24. Slattery ML, Kinney AY, Levin TR. Factors associated with colorectal cancer screening in a population-based study: the impact of gender, health care source, and time. Prev Med. 2004; 38(3): 276-283. S0091743503003128 [pii]. 10.1016/j.ypmed.2003.11.009 [PubMed: 14766109]

25. Cockburn J, Paul C, Tzelepis F, McElduff P, Byles J. Screening for bowel cancer among NSW adults with varying levels of risk: a community survey. Aust N Z J Public Health. 2002; 26 (3): 236-241. [PubMed: 12141619]

26. Public Health Division, Report on the 1997 and 1998 NSW Health Surveys. NSW Health Department; Sydney: 2000. Available at: http://www.health.nsw.gov.au/public-health/nswhs/ hsindex.htm

27. Weber MF, Banks E, Ward R, Sitas F. Population characteristics related to colorectal cancer testing in New South Wales, Australia: results from the 45 and Up Study cohort. J Med Screen. 2008; 15(3):137-142. 15/3/137 [pii]. 10.1258/jms.2008.008050 [PubMed: 18927096]

28. Vernon SW, Briss PA, Tiro JA, Warnecke RB. Some methodologic lessons learned from cancer screening research. Cancer. 2004; 101(5 Suppl):1131-1145.10.1002/cncr.20513 [PubMed: 15316907]

29. Thomas RJ, Clarke VA. Colorectal cancer: a survey of community beliefs and behaviours in Victoria. Med J Aust. 1998; 169 (1):37-40. [PubMed: 9695701]

30. Schattner A, Gilad A. Primary care physicians' awareness and implementation of screening guidelines for colorectal cancer. Preventive medicine. 2002; 35 (5):447-452. [PubMed: 12431893]

31. Giveon S, Kahan E. Patient adherence to family practitioners' recommendations for breast cancer screening: a historical cohort study. Fam Pract. 2000; 17 (1):42-45. [PubMed: 10673487]

32. Snell JL, Buck EL. Increasing cancer screening: a meta-analysis. Preventive medicine. 1996; 25(6):702-707.10.1006/pmed.1996.0109 [PubMed: 8936572]

33. Olynyk JK, Aquilia S, Platell CF, Fletcher DR, Henderson S, Dickinson JA. Colorectal cancer screening by general practitioners: comparison with national guidelines. Med J Aust. 1998; 168 (7):331-334. [PubMed: 9577443] 
34. New South Wales Population Health Survey 2009 (HOIST). Centre for Epidemiology and Research, NSW Department of Health; Available at http://www.health.nsw.gov.au/PublicHealth/ surveys/hsa/09/toc/t_2_beh_04_cancer_prostate_bowel.asp

35. Courtney RJ, Paul CL, Sanson-Fisher RW, Macrae FA, Carey ML, Attia JR, McEvoy MA. Colorectal cancer screening in Australia: a community-level perspective. The Medical Journal of Australia. 2012; 196 (8):516-520. [PubMed: 22571309]

36. Cabana MD, Rand CS, Powe NR, Wu AW, Wilson MH, Abboud PA, Rubin HR. Why don't physicians follow clinical practice guidelines? A framework for improvement. JAMA. 1999; 282(15):1458-1465. jrv90041 [pii]. [PubMed: 10535437]

37. Ee HC, Olynyk JK. Making sense of differing bowel cancer screening guidelines. Med J Aust. 2009; 190(7):348-349. ee10002_fm [pii]. [PubMed: 19351305]

38. Australian Institute of Health and Welfare \& Australian Government Department of Health and Ageing. Cancer series no. 49. Cat. no. CAN 45. Canberra: AIHW; 2009. National Bowel Cancer Screening Program: annual monitoring report 2009.

39. Mobley L, Kuo TM, Urato M, Boos J, Lozano-Gracia N, Anselin L. Predictors of endoscopic colorectal cancer screening over time in 11 states. Cancer causes \& control: CCC. 2010; 21(3): 445-461.10.1007/s10552-009-9476-y

40. Vernon SW. Participation in colorectal cancer screening: a review. Journal of the National Cancer Institute. 1997; 89 (19):1406-1422. [PubMed: 9326910]

41. Slattery ML, Kinney AY, Levin TR. Factors associated with colorectal cancer screening in a population-based study: the impact of gender, health care source, and time. Preventive medicine. 2004; 38(3):276-283.10.1016/j.ypmed.2003.11.009 [PubMed: 14766109]

42. Beydoun HA, Beydoun MA. Predictors of colorectal cancer screening behaviors among averagerisk older adults in the United States. Cancer causes \& control: CCC. 2008; 19(4):339359.10.1007/s10552-007-9100-y

43. Guessous I, Dash C, Lapin P, Doroshenk M, Smith RA, Klabunde CN. Colorectal cancer screening barriers and facilitators in older persons. Preventive medicine. 2010; 50(1-2):3-10.10.1016/ j.ypmed.2009.12.005 [PubMed: 20006644]

44. Holden DJ, Jonas DE, Porterfield DS, Reuland D, Harris R. Systematic review: enhancing the use and quality of colorectal cancer screening. Annals of internal medicine. 2010; 152(10):668676.10.1059/0003-4819-152-10-201005180-00239 [PubMed: 20388703]

45. Fisher DA, Judd L, Sanford NS. Inappropriate colorectal cancer screening: findings and implications. Am J Gastroenterol. 2005; 100(11):2526-2530. AJG322 [pii]. 10.1111/j. 1572-0241.2005.00322.x [PubMed: 16279910]

46. Viiala CH, Zimmerman M, Cullen DJ, Hoffman NE. Complication rates of colonoscopy in an Australian teaching hospital environment. Internal medicine journal. 2003; 33 (8):355-359. [PubMed: 12895166]

47. The National Bowel Cancer Screening Program Quality Working Group. Improving Colonoscopy Services in Australia. Australian Government Department of Health and Ageing; Canberra: 2009. Available at: http://www.cancerscreening.gov.au/internet/screening/publishing.nsf/Content/nbcsimp-col-ser-0709-cnt

48. The Age. Call for better bowel cancer screening. May 11. 2011 Available at:http:// news.theage.com.au/breaking-news-national/calls-for-better-bowel-cancerscreening-20110511-1ej1h.html

49. Barrett T. Bowel cancer screening programme under threat in Australia. Lancet Oncol. 2011; 12 (2):123. [PubMed: 21355127]

50. Flitcroft KL, Salkeld GP, Gillespie JA, Trevena LJ, Irwig LM. Fifteen years of bowel cancer screening policy in Australia: putting evidence into practice? Med J Aust. 2010; 193(1):37-42. fli11426_fm [pii]. [PubMed: 20618113] 


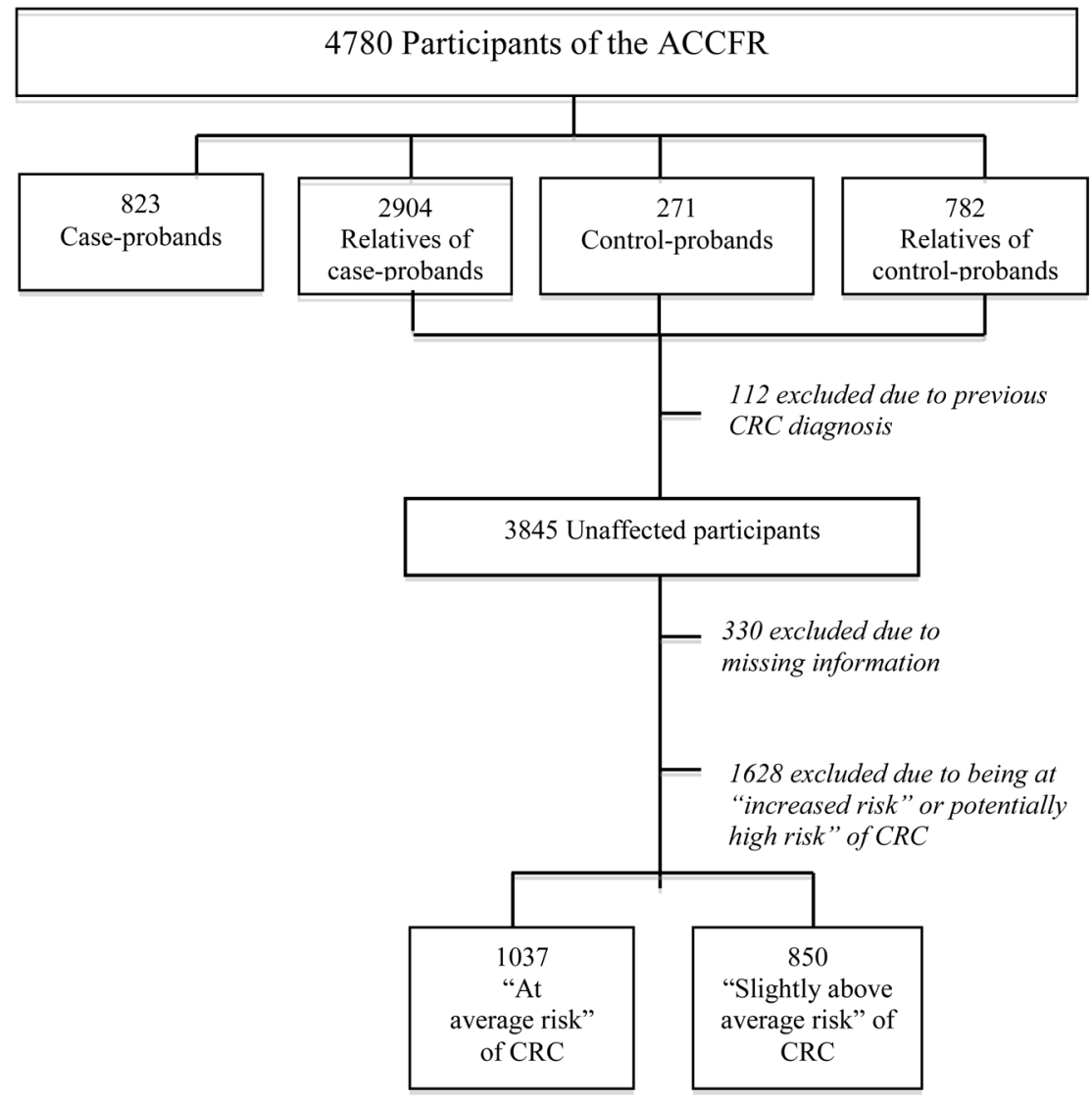

Figure 1.

Flowchart of participants' selection 
a) Subjects at average risk of CRC

"Sigmoidoscopy "FOBT = Colonoscopy "Any screening test

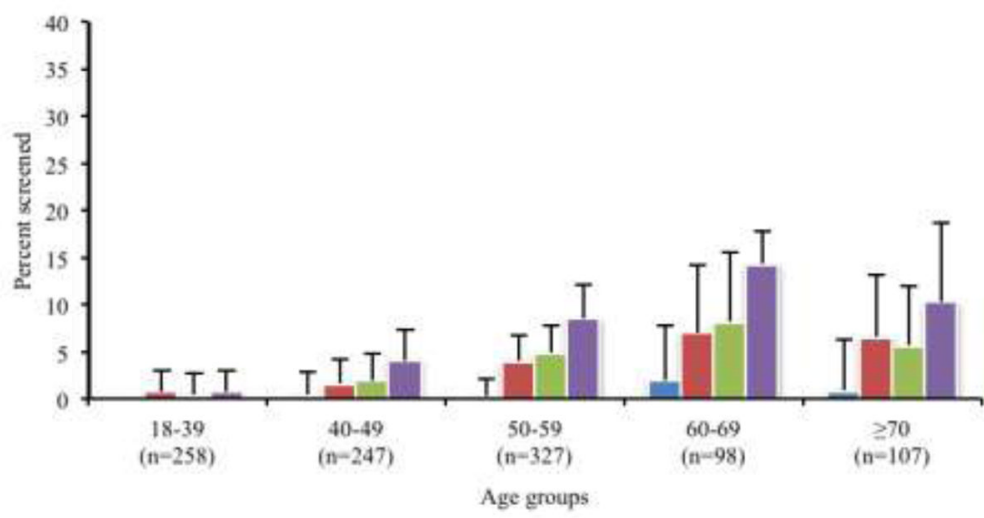

b) Subjects slightly above average risk of CRC

"Sigmoidoscopy "FOBT "Colonoscopy = Any screening test

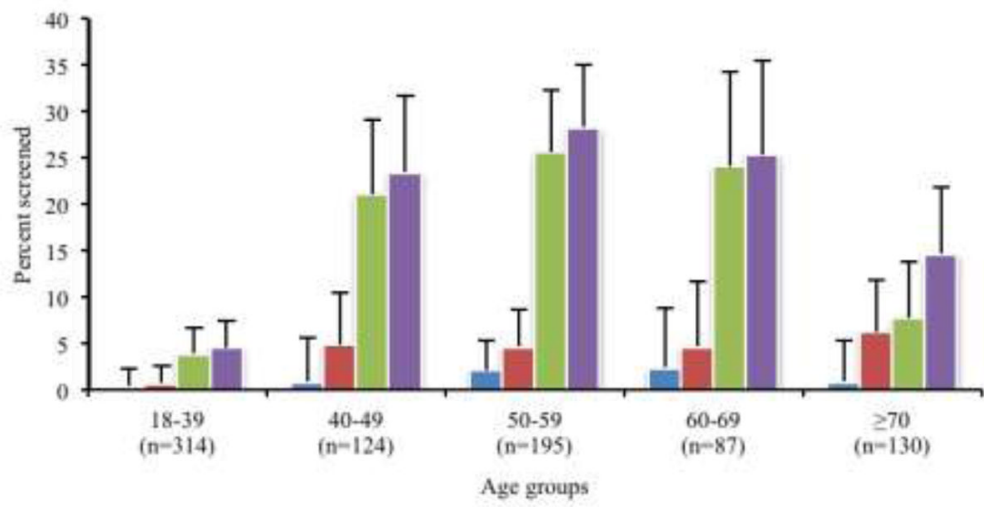

Figure 2.

Level of CRC screening participation by age and modality 


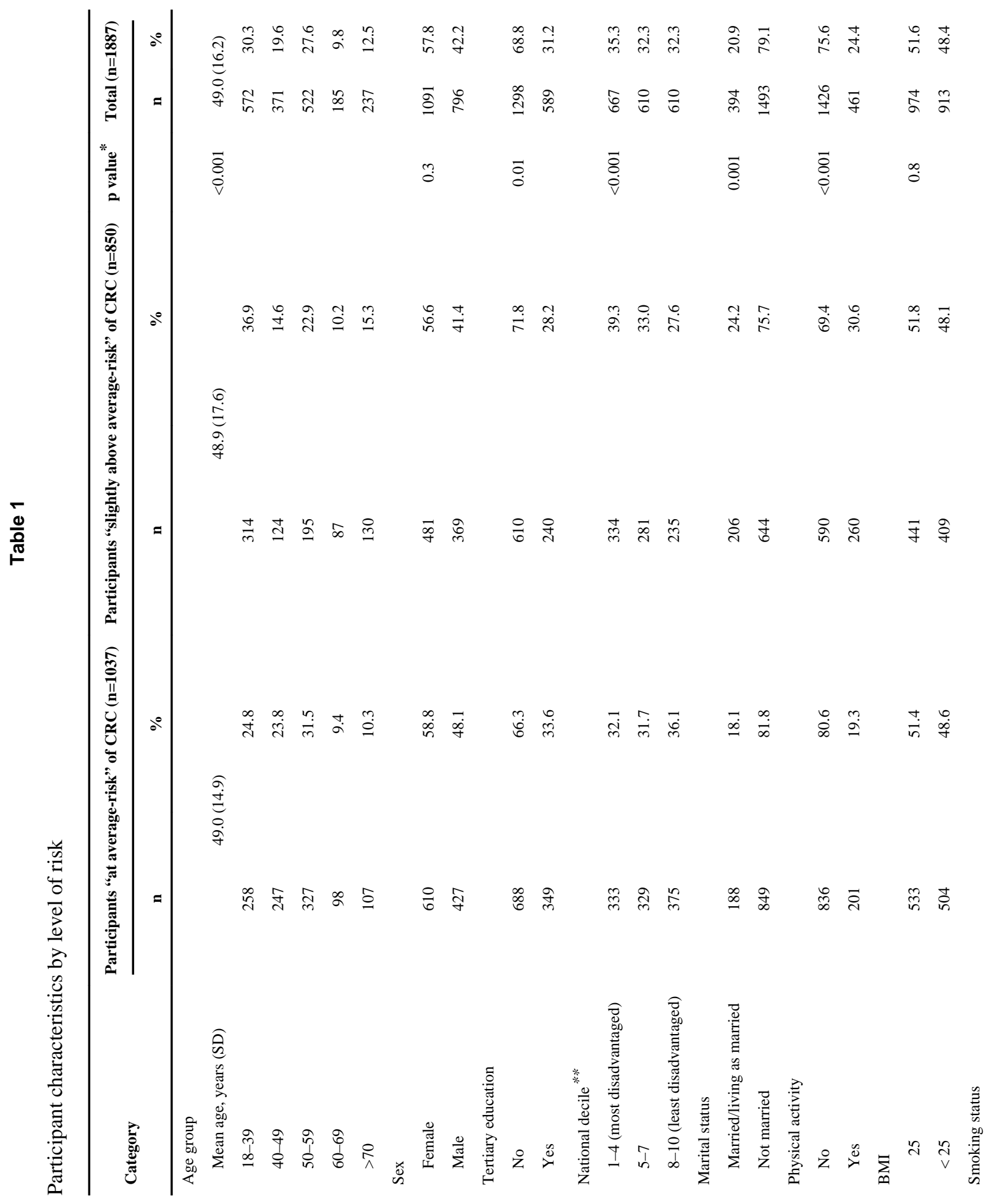


OUAKRIM et al.

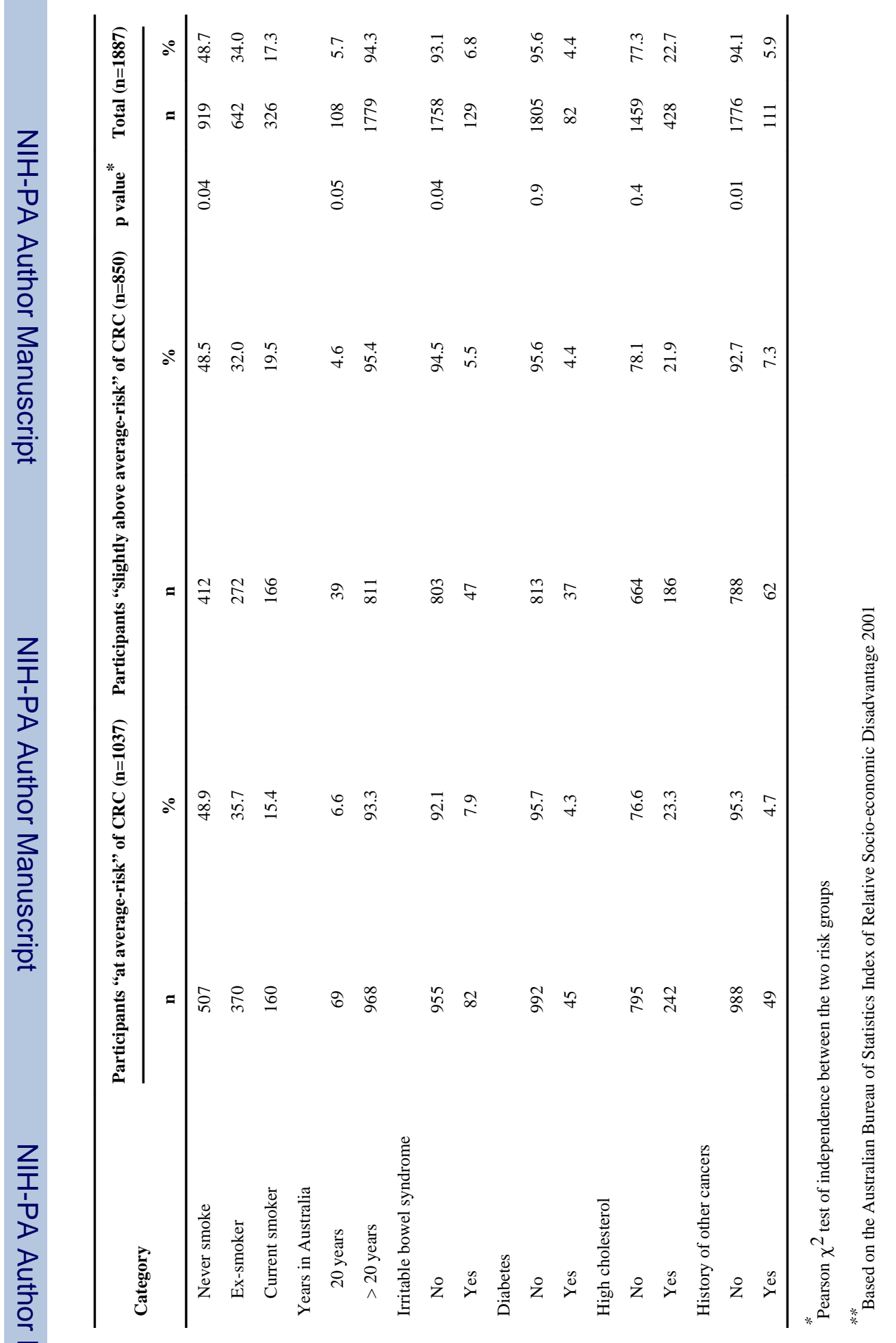

Cancer Causes Control. Author manuscript; available in PMC 2013 November 01. 


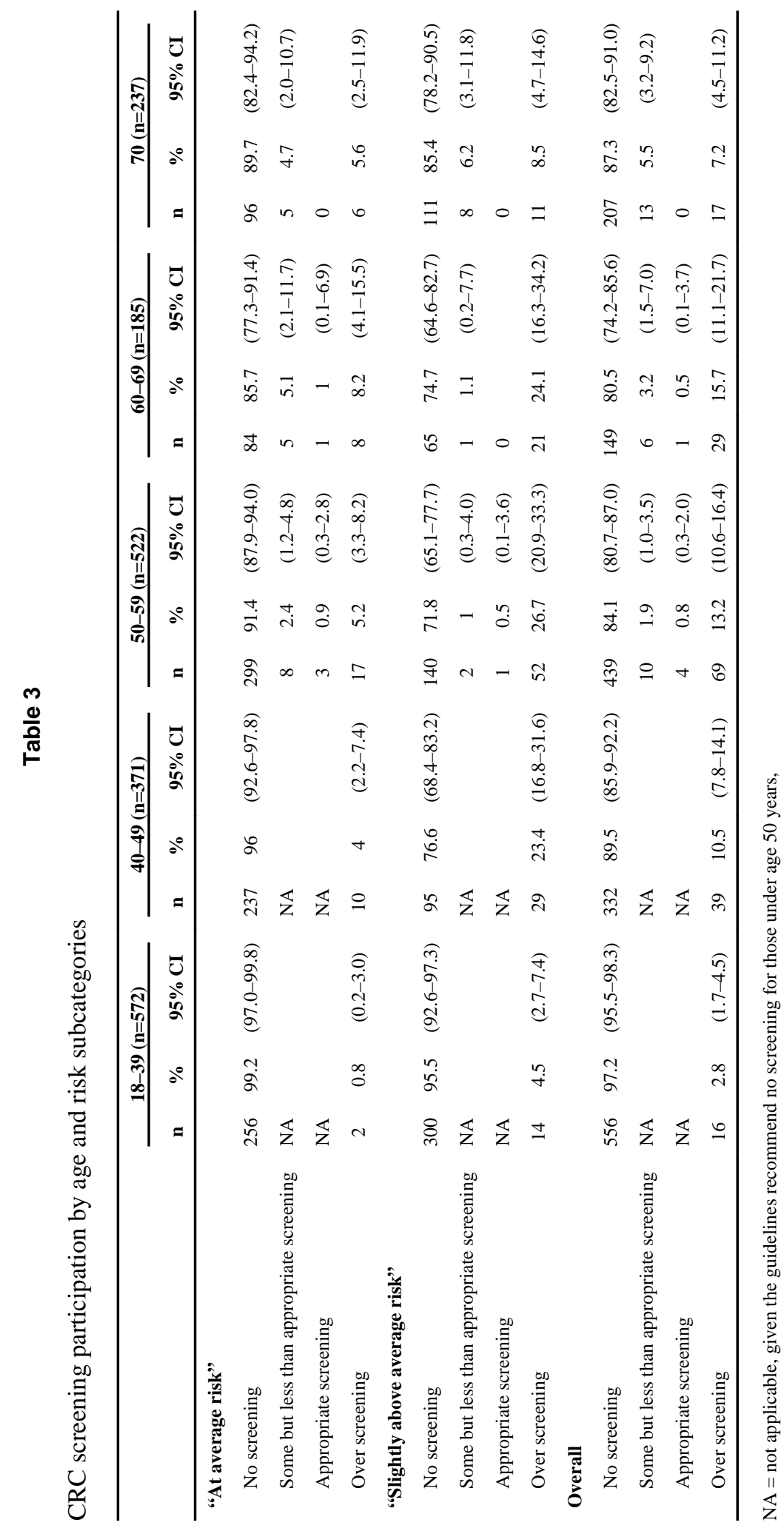


Table 4

Results of logistic regression analysis * of factors associated with over-screening for CRC

\begin{tabular}{lccc}
\hline Predictors & \multicolumn{2}{c}{ Over screening vs. No screening } \\
\hline & OR & $\mathbf{9 5 \%}$ CI & P value \\
\cline { 2 - 4 } Age group & & & \\
$18-39$ & 1 & & \\
$40-49$ & 5.56 & $(3.00-10.31)$ & $<0.001$ \\
$50-59$ & 6.69 & $(3.90-12.51)$ & $<0.001$ \\
$60-69$ & 7.25 & $(3.69-14.25)$ & $<0.001$ \\
$>=70$ & 2.96 & $(1.42-6.17)$ & 0.004 \\
Education & & & \\
No tertiary education & 1 & & \\
Tertiary education & 1.73 & $(1.21-2.47)$ & 0.002 \\
Family history of CRC & & & \\
No & 1 & & \\
Yes & 5.34 & $(3.68-7.76)$ & $<0.001$ \\
High cholesterol & & & \\
No & 1 & & \\
Yes & 1.54 & $(1.06-2.22)$ & 0.02 \\
\hline Parsimonious model only & & & \\
\hline
\end{tabular}

